\title{
НЕСКОЛЬКО ОСМАНСКИХ ДОКУМЕНТОВ О ПОСЕЛЕНИИ ОСЕТИН В АНАТОЛИИ
}

\section{Г. В. Чочиев}

В статье представлены документы из Османского архива при кабинете премьер-министра Туриии, относящиеся к поселению осетин в Центральной и Восточной Анатолии в начале 60-х гг. ХІХ в. Выявление свидетельств об осетинских иммигрантах в османских источниках является непростой задачей ввиду прежде всего специфики отражения в них кавказской этнической номенклатурь. На данный момент нами обнаружено не более десятка документов, содержащих информаиию об осетинских субэтнических и кланово-сословных группах (дигориах, тагауриах / тагиатах, баделиатах), трактуемых обычно как «племена» в рамках более чирокого сообщества "черкесских мухаджиров». Несмотря на ограниченность данного корпуса, в нем получил отражение ряд немаловажных аспектов иммиграции, колонизации и адаптации переселенцев в османском государстве: способы $и$ критерии выьора мест поселения, стремление общин к сохранению единства, опека властями традииионной знати и мусульманского духовенства, религиозная и образовательная интеграция, земельные противоречия с местным населением, попытки возвращения на родину и др. В случае продолжения исследований можно ожидать - с учетом регулярного открытия новых архивных фондов - некоторого расширения объема известных материалов по указанной теме.

Ключевые слова: Османская империя, Анатолия, осетины, черкесы, иммиграция, колонизация, архивные источники.

The article presents several documents from the Turkish Republic Prime Ministry Ottoman Archives related to the settlement of Ossetians in Central and Eastern Anatolia at the beginning of 1860s. The identification of the evidence on Ossetian immigrants in the Ottoman sources is a complicated task due primarily to the specificities of reflection of the Caucasian ethnic nomenclature there. So far we have found not more than a dozen of documents containing information about Ossetian subethnic and clan-caste groups (Digorians, Tagaurians / Tagiatas, Badeliatas) usually referred to as «tribes» within the wider entity of «Circassian Muhajirs». Despite the limited nature of the body of available information, it still reflects a number of important aspects of the resettlement, colonization and adaptation of the migrants in the Ottoman state: methods and criteria for selecting the places of settlement, tendency to preserve communal unity, guardianship by the authorities of the traditional nobility and Muslim clergy, religious and educational integration, land conflicts with the local population, attempts to return to the homeland, etc. In case of further research - given that the opening of new archival collections is being witnessed regularly - some expansion of the scope of the known materials on the topic could be expected.

Keywords: Ottoman Empire, Anatolia, Ossetians, Circassians, immigration, colonization, archival sources.

В настоящей статье представлены документы из Османского архива при кабинете премьер-министра Турецкой Республики (Т.C. Başbakanlık Osmanlı Arşivi), имеющие прямое отношение к иммиграции, расселению и адаптации осетинских групп в Османской империи, в частности в Центральной и Восточной Анатолии, в середине позапрошлого века.
В основных чертах эмиграция части осетин с их родины в султанские владения освещена в отечественной историографии ${ }^{1}$. Она происходила в несколько этапов главным образом в период с 1858 по 1862 г. и затем в 1865 г. Общее число переселенцев едва ли превысило 5 тыс. человек. Очевидно также, что эта миграция имела место в русле гораздо более масштабного явления - мас- 
сового исхода горцев Северного Кавказа в османские пределы на финальной стадии и после Кавказской войны (так называемого мухаджирства), хотя в переселении осетин решающую роль сыграли, безусловно, не столько военно-политические, сколько социально-экономические и религиозные факторы и мотивы.

Следует отметить, что выявление и отслеживание свидетельств об осетинских общинах в османских источниках представляет для исследователя крайне непростую задачу. Это объясняется не только сравнительной немногочисленностью осетин в общей массе выходцев из региона, но и особенностями регистрации властями страны своих новых подданных и спецификой отражения кавказской этнической номенклатуры в официальной документации.

K середине XIX в. османское государство имело давнюю традицию и немалый опыт приема, обустройства и интеграции значительных контингентов внешних и внутренних переселенцев самого разного происхождения, вероисповедания и стату$\mathrm{ca}^{2}$. В рамках бюрократического механизма миграционной и колонизационной политики Порты применялась довольно детализированная методика учета прибывающего в страну либо перемещаемого внутри ее границ населения. Чиновникам на местах предписывалось по возможности полно и точно фиксировать этногеографическую принадлежность, личности предводителей, численность, половозрастной состав, имущественное и социальное положение членов мигрирующих общин, а также объемы выделяемой им помощи, районы временного и постоянного размещения и т.п. Несмотря на существенные погрешности и издержки, неизбежные в периоды особо интенсивного или неожиданного притока мигрантов извне (в том числе в пиковые годы кавказского мухаджирства), эта система продемонстрировала в целом приемлемый уровень эффективности в первичной идентификации пришлых групп и регулировании их дальнейших перемещений по территории империи вплоть до окончательного поселения. В то же время в силу того, что вовлеченные в решение данной проблемы османские служащие преследовали, как правило, сугубо практические, краткосрочные цели, в вышедших из-под их пера материалах зачастую наблюдаются разнобой и непоследовательность в обозначении переселенческих общин. Так, для их «маркировки» могли использоваться этническое или субэтническое наименование, регион исхода, название доминирующего клана или сословия, имя традиционного или духовного лидера или же комбинация этих и подобных признаков. Часты и случаи искаженного (иногда до неузнаваемости) написания слов, выражающих незнакомые составителям документов специфические понятия и феномены.

В источниках, касающихся северокавказских иммигрантов, практически всегда присутствует указание на их происхождение: этническое (черкес, абаза, лезги, чечен и др.) или - реже - географическое (Кабкасья, Черкесистан, Дагыстан, Кубан, Анапа и др.). Вместе с тем очевидна тенденция к употреблению термина «черкес» как суперэтнонима, включающего в себя не только адыгов (черкесов в строгом смысле), но и других кавказцев, что вполне естественно, поскольку исторически именно адыги-черкесы были лучше других народов региона знакомы османцам и именно они составляли абсолютное большинство переселяющихся горцев. При этом во многих случаях для конкретизации содержания данного общего обозначения приводятся и более узкие «племенные» или «родовые» наименования, в качестве которых могут выступать названия как адыгских субэтносов, так и не относящихся к ним народов и групп. К примеру, в документах 1850-х - 1870-х гг. наряду с оборотами типа «черкесские мухаджиры племени абадзехов (шапсугов, бжедухов, кабардинцев и т.д.)» встречаются и такие сочетания, как «черкесы малочеченского племени», «мухаджиры черкесского племени абазин», «дагестанские черкесы» и т.п. Впрочем, названия неадыгских народностей, равно как и адыгских «племен», нередко фигурируют в документах самостоятельно, без зонтич- 
ного определения «черкесы/черкесский» (таких материалов об осетинах, правда, на сегодняшний день не найдено, о чем подробнее говорится ниже). С другой стороны, не подлежит сомнению, что под именем «черкесы» в действительности также порой «скрываются» представители абазинских, осетинских, чеченских, карачаевских или дагестанских общин, хотя их истинную принадлежность возможно установить лишь в единичных случаях при наличии в тексте каких-либо информативных лингвистических, антропонимических и топонимических подробностей.

Что касается осетинских переселенцев, то о них нам удалось обнаружить не более десятка недвусмысленных упоминаний среди нескольких тысяч документов по кавказскому мухаджирству, представленных в каталогах указанного архива. Ни в одном из этих источников не содержатся общеосетинские эндо- или экзоэтнонимы в какой бы то ни было известной форме. Поэтому критериями для отождествления описываемых в этих документах групп с осетинами служат их субэтнические и/или кланово-сословные наименования, под которыми они (точнее, их лидеры), по-видимому, сами предпочли представить себя османским инстанциям. Отмечены, в частности, три термина подобного типа, а именно: дигорцы (в двух документах в виде ديغور, в одном ошибочно - дебгор دبغور); тагаурцы или тагиаты (в трех документах в форме теги/теки تكى, в одном - тегаи/ meкаи تكاى); баделиаты (в единственном документе как бадилан باديلان). Во всех без исключения случаях данные группы квалифицируются османскими чиновниками как «племена» (кабиле), входящие в более широкое многоплеменное сообщество «черкесских мухаджиров» (черкес мухаджирлери или мухаджирин-и черакисе). Помимо этого, основанием для идентификации тех или иных партий северокавказских иммигрантов как осетин могут выступать упоминаемые в документах названия населенных пунктов, достоверно известных как населенные осетинами из других письменных или устных источников. Нами был выявлен всего один документ такого рода, но полноценный поиск по этому критерию в архивных каталогах пока не проводился.

Далее в хронолого-тематическом порядке будет охарактеризовано содержание вышеназванных материалов. Разумеется, они отнюдь не отражают всей картины и всех перипетий осетинской колонизации в Османской империи, а лишь дают фрагментарное представление о некоторых аспектах расселения и интеграции переселенцев на новой родине.

Документ № 1: «Направление части черкесских мухаджиров для поселения в Сивас» (11 сафера 1277 г.х. / 29 августа 1860 г.) [4].

Содержит решение правительства об отправке некоторых из скопившихся в черноморском порте Самсун черкесских мухаджиров в Сивасский вилайет с целью их постоянного поселения там. Названы следующие «племена»: тагаурцы (теги), малочеченцы (чечен-и сугра), кабардинцы (кабартай) и дагестанцы (дагыстан). Количественные параметры групп не указаны.

Документ № 2: «Поселение племени теги из черкесских мухаджиров в Сивасе и оказание уважения и внимания ходже Ибрагим-эфенди» (17 сафера 1277 г.x. / 4 сентября 1860 г.) [5].

Представляет собой письмо председателя Мухаджирской комиссии ${ }^{3}$ Хафыз-паши великому везиру (главе правительства) относительно коллизии, возникшей в упомянутой в предыдущем документе группе тагаурцев в связи с тем, что один из ее лидеров ходжа Ибрагим-эфенди, характеризуемый как видный мусульманский ученый-богослов (алем-уль-улема), незадолго до отбытия мухаджиров из Самсуна в Сивасский вилайет обратился к властям с просьбой поселить его отдельно от соплеменников в Дамаске. В изъявлении им такого желания, в сущности, нет ничего неожиданного, поскольку Порта, проявляя подчеркнутую заботу о прибывающих в страну лицах духовного звания, обычно разрешала им выбрать в качестве мест постоянного жительства такие важные исламские центры, как Стамбул, Дамаск, Бурса, 
Мекка, Медина и др. Однако в рассматриваемом случае положение осложнило нежелание остальной части общины расставаться со своим ходжой (вполне возможно, одним из инициаторов переселения) «ввиду испытываемой к нему привязанности». В результате усилий местных служащих, которые были явно встревожены данными разногласиями, Ибрагим-эфенди удалось убедить отказаться от его намерения. В качестве же своего рода компенсации ему были даны дополнительные гарантии государственной «милости и благосклонности» при обустройстве вместе со своей группой в Сивасе.

Документ № 3: «Поселение ходжи Ибрагим-эфенди из черкесских мухаджиров вместе со своим племенем в Сивасе» (18 сафера 1277 г.х. / 5 сентября 1860 г.) [7].

Содержит распоряжение правительства мутасаррыфу (главе администрации) центрального санджака (округа) Сивасского вилайета Ахмед-паше принять необходимые меры к должному поселению направляемых из Самсуна мухаджиров и оказанию обещанной помощи их лидеру ходже Ибрагим-эфенди.

Документ № 4: «Выделение продолжающим прибывать с Кавказа в Трабзон черкесским мухаджирам денег из местных фондов в дополнение к уже расходуемым на их нужды средствам, собранным для пострадавших при эрзурумском землетрясении» (17 сафера 1277 г.x. / 4 сентября 1860 г.) [8].

В докладной записке руководства Трабзонского вилайета в великий везират перечислены некоторые из «племен», находящихся в порте Трабзон: абазины-тапанта (алтыкесек), абуд (?), баделиаты (бадилан), большечеченцы (чечен-и кюбра), кабардинцы (кабартай). Сообщается, что для покрытия расходов на их прием были привлечены первоначально финансы из фонда помощи жертвам разрушительного землетрясения 1859 г. в Эрзуруме, а после обнаружения их недостаточности - также и ресурсы различных денежных фондов вилайета. Благодаря этому была возмеще- на стоимость перевозки мухаджиров по морю, организовано питание прибывающих и назначены поденные пособия им в размере двух гурушей ${ }^{4}$ для взрослых и одного гуруша для детей до пятнадцати лет.

В приложении к записке приведены численность и половозрастной состав переселенцев. Интересующая нас группа «бадилан» насчитывала 98 человек, в том числе 51 мужского и 47 женского пола и 54 взрослых и 44 ребенка (т.е. лиц старше и младше пятнадцатилетнего возраста). Поскольку сведения о посемейном распределении и социально-имущественных характеристиках данного населения отсутствуют, представляется проблематичным судить о том, включало ли в себя указанное число исключительно членов баделиатских родов и их ближайших родственников или еще и какое-то количество последовавших за ними представителей зависимых сословий.

Как явствует из примечания составителя документа, группа собиралась в ближайшее время снарядить четырех человек из своей среды в Эрзурумский и Сивасский вилайеты с целью поиска подходящего для постоянного поселения места и просила власти выдать им разрешения на путешествие и предоставить одного проводника.

Документ № 5: «Перемещение расселенных в селах Ташабада черкесских мухаджиров в какое-либо устраивающее их место в районах Текманской равнины, Ахлата и Терджана» (7 мухаррема 1278 г.x. / 15 июля 1861 г.) [9].

Представлена переписка между региональными и центральными инстанциями в связи с прошением 160 дигорских семейств, размещенных ранее в казе (уезде) Ташабад Сивасского санджака, о переводе их в другую местность. Хотя иммигранты обосновывали свое требование ссылками на «нищету», в которую они якобы впали из-за неблагоприятных природно-климатических условий региона, непосредственным толчком для их обращения к властям стало полученное ими известие о поселении другой части того же «племени» в Карсском санджаке Эрзурумского вилайета. Именно после этого ими были направ- 
лены в Эрзурум депутаты из числа знати Мурад-бей, Муса-бей и Хасан-бей для решения вопроса о перепоселении группы ближе к вновь прибывшим соплеменникам, что явно указывает на то, что доминирующим мотивом действий мухаджиров выступало стремление к восстановлению этносоциальной (общинной) целостности. Однако, поскольку для Порты сосредоточение в приграничном с Россией районе слишком большого массива кавказских горцев было чревато осложнениями во взаимоотношениях с северным соседом, упомянутой группе было предложено вместо карсского региона выбрать для себя любое удобное для поселения место в южной части Эрзурумского вилайета - в казах Текман, Терджан или Ахлат.

Документ № 6: (запись в журнале регистрации входящей переписки правительства с Мухаджирской комиссией от 7 ребиульэввеля 1278 г.х. / 12 сентября 1861 г. [10]).

Содержится информация о поселении в расположенном в Сарыкамышской казе Карсского санджака селе Хамамлы и на прилегающей к нему равнине (Хамамльдюзю) около 400 семейств «черкесского племени дигор». По всей вероятности, это и есть основная группа дигорских переселенцев, с которой пытаются воссоединиться упоминаемые в предыдущем и двух следующих (см.) документах семейства, оказавшиеся в Сивасе.

Документ № 7: «Небезопасность расселения части черкесских мухаджиров вблизи российской границы и предпочтительность их поселения в казах Текман, Ахлат или Терджан либо ином подходящем месте» (7 шабана 1278 г.х. / 7 февраля 1862 г.) [11].

Из докладной записки вали (губернатора) Эрзурумского вилайета Хайреддин-паши в великий везират следует, что проблема окончательного поселения 160 семейств дигорцев, первоначально направленных в сивасский регион, по прошествии более чем полугода все еще не получила решения. Более того, за это время события приобрели некоторый драматизм, поскольку данная группа самовольно покинула выделенные ей земли и двинулась на восток в сторону Карса и российской границы. Не доходя до Эрзурума, однако, беглецы были остановлены, и одна их половина (80 семейств) временно размещена под Эрзинджаном, а вторая - в районе Испира. Дальнейшая их судьба была предметом серьезных разногласий. Если провинциальная администрация уговаривала их остаться в указанных местах или отправиться в уже предлагавшиеся им более южные области вилайета, то сами мухаджиры категорически настаивали на поселении в казе Сaрыкамыш Карсского санджака, где успели обосноваться их соплеменники. При этом у властей, в дополнение к опасениям по поводу реакции российской стороны, появилась и новая веская причина не желать увеличения числа северокавказцев в названном районе. В частности, судя по содержащейся в досье переписке, в предшествующие месяцы имели место попытки (частью успешные) поселенных в Сарыкамыше горцев-иммигрантов легально или нелегально перейти границу в обратном направлении, а также факты целенаправленного стремления сюда под различными предлогами кавказских групп из других, в том числе весьма отдаленных, областей Анатолии, с явным, хоть и не декларируемым, расчетом вернуться на родину. Исходя из этих соображений, Хайреддин-паша решительно возражал против удовлетворения подобных просьб.

Упомянутая община дигорцев, однако, также не собиралась отказываться от своего намерения. В направленном ее лидерами в Стамбул прошении отмечалось, что лишь Сарыкамыш и его окрестности полностью подходят для проживания и хозяйственной деятельности их «племени», так как «богаты пастбищами, водой и лесом». В случае поселения там мухаджиры планировали обеспечивать себя средствами к существованию за счет заготовки дров в горном массиве Соганлыдаг и их продажи в Карс и Эрзурум и обещали «обжить и благоустроить» регион. Одновременно власти заверялись в том, что переселенцы 
никоим образом не помышляют об отказе от османского подданства и возвращении в Россию, а если какая-либо семья все-таки пойдет на такой шаг, то она, даже при наличии у нее уважительных причин для этого, должна будет под контролем и при содействии знати вернуть в казну все средства, потраченные на ее обустройство государством и местным населением.

Документ № 8: «Поселение направленных в Эрзурум черкесских мухаджиров в Текмане, Ахлате или Терджане ввиду неприемлемости их поселения в близких к границе Соганлыдаге, Хамамлы и Сарыкамыше» (19 шабана 1278 г.х. / 19 февраля 1862 г.) [12].

В совместном письме в великий везират вали Хайреддин-паша и командующий Анатолийской армией мюшир (маршал) Мустафа-паша в очередной раз перечисляют возможные риски для государства от поселения в районе Сарыкамыша названных 160 семейств (фигурирующих в этом документе как «черкесские мухаджиры» без этнического уточнения). По убеждению обоих высокопоставленных служащих, основанному на проведенном ими расследовании, проявляемая в этом вопросе переселенцами настойчивость является следствием «интриг и подстрекательств» их предводителей и не должна приниматься во внимание Портой 5 .

Документ № 9: «О строительстве мечетей и школ для мухаджиров в Карсском санджаке» (23 реджеба 1281 г.х. / 22 декабря 1864 г.) [13].

В многостраничном досье содержатся сведения о некоторых сторонах социокультурной адаптации «черкесских» иммигрантов, размещенных несколькими годами раньше в селах карсско-сарыкамышского региона. «Племенная» принадлежность поселенцев не указана, однако осетинский характер ряда перечисленных в документе населенных пунктов достаточно надежно подтверждается различными печатными и полевыми материалами. К их числу относятся такие селения, как Сарыкамыш, Хамамлы, Бозат, Селимкей, Алисофу, Гекчехарман, Олуклу. Об этническом составе в рассматриваемый период остальных упомянутых в тексте сел (Едикилисе, Ялнызчам, Тепеджик, Акпынар, Эгридже, Гюллю и др.) мы не располагаем никакими данными, но допускаем, что в них могли быть расселены как осетины, так и - с большей вероятностью - дагестанцы, чеченцы или кабардинцы.

В письме мутасаррыфа Карсского санджака Эмин-паши в Мухаджирскую комиссию сообщалось, что благодаря значительной материальной помощи местного населения прибывшие сюда северокавказцы в короткий срок смогли обзавестись жильем и сельскохозяйственным инвентарем и уже способны выплачивать десятину (amap) от самостоятельно произведенной на предоставленных им государством землях продукции. Соответственно, взаимоотношения между мухаджирами и коренными жителями характеризуются как вполне комплементарные. В письме также отмечалось, что поселенные в регионе северокавказцы «...обладают способностями к образованию и цивилизации, их еда чиста и свежа, и они в состоянии выставить пятьсот всадников на самых отборных лошадях». После этого хвалебного отзыва о новых подданных обращалось внимание на необходимость удовлетворения их духовных потребностей посредством строительства в основных иммигрантских селах (названы в частности Сарыкамыш, Хамамлы, Тепеджик и Ялнызчам) мечетей и примечетных начальных школ. При этом предполагалось возместить из местной казны лишь стоимость работы плотников, в то время как строительные материалы готовы были приобрести на свои средства сами сельчане. Им же в дальнейшем предстояло выплачивать жалованье муллам и преподавателям (обе эти функции обычно исполнялись одним и тем же лицом, именуемым по-турецки «ходжа»).

Эмин-пашой был поставлен перед Портой еще один вопрос, прямо связанный с интеграцией переселенцев в османский социум. Речь шла о приеме 11 мальчиков из знатных семей, проживающих в указанных селах, в столичные военные школы («как 
это сделано по высочайшей милости в отношении других, подобных им»), что, по мнению османского чиновника, стало бы «...причиной особой гордости данного населения». Подчеркивалось, что все кандидаты успешно освоили турецкий язык, по меньшей мере однажды прочитали от начала до конца Коран и отличались бесспорной тягой к просвещению. Однако в результате переписки с соответствующими ведомствами выяснилось, что в текущем году в военных учебных заведениях Стамбула не осталось свободных мест. Ввиду этого по рекомендации командующего Анатолийской армией было принято решение направить детей на учебу в другие города страны - Бурсу, Эдирне, Битолу и Дамаск.

Оба предложения были поддержаны Мухаджирской комиссией и великим везиратом и утверждены специальным султанским рескриптом.

Документ № 10: «Направление ходатайства о предотвращении посягательств на земли, на которых в Карсе поселены некоторые беи из черкесских мухаджиров племени тегаи» (15 шевваля 1281 г.x. / 13 марта 1865 г.) [14].

Представляет собой краткое изложение докладной записки вали Эрзурумского вилайета в великий везират по поводу полученной из Карсского санджака информации об имеющем место «вмешательстве» в землевладельческие права поселенных там представителей тагаурского (тегаu) «племени» по имени Касполат-бей, Али-бей, Махмуд-бей и Муса-бей и необходимости пресечения этих незаконных действий и оказания названным лицам дополнительной материальной помощи. Титул «бей» после имен определенно указывает на принадлежность их владельцев к знатной прослойке в пределах своей общины. Сведения о том, с чьей стороны исходили и в чем заключались посягательства на их земельную собственность, в документе отсутствуют, но речь, безусловно, идет о какой-то группе местного населения, имевшей свои виды на выделенные мухаджирам участки. Очевидна проиммигрантская позиция властей в конфликте.

Этим в основном исчерпывается круг документов о поселении осетин в Османской империи, в частности в Анатолии, обнаруженных нами в ходе изучения фондов вышеупомянутого архива главным образом в течение первой половины 2000-х гг. При всей ограниченности представленного корпуса источников в нем получил отражение ряд немаловажных аспектов иммиграции, колонизации и адаптации переселенческих групп в этом государстве, как то: способы и критерии выбора мест поселения, стремление общин к сохранению единства, опека властями традиционной знати и мусульманского духовенства, религиозная и образовательная интеграция, земельные противоречия с местным населением, попытки возвращения на родину и др. Несомненно, что в случае продолжения поисковой работы можно ожидать - с учетом регулярного открытия для исследователей все новых архивных фондов определенного пополнения количества известных нам материалов по интересующей нас здесь теме. Несмотря на то, что рассчитывать на всестороннее отображение в них процесса осетинского мухаджирства не приходится в силу названных в первой части статьи причин, содержащиеся в Ocманском архиве документы потенциально все же могут быть достаточно информативны (в том числе в плане сопоставления с данными отечественных источников) с точки зрения прояснения различных обстоятельств и деталей этого явления, а возможно - и более точной характеристики некоторых черт осетинского общества указанного периода в целом. 


\section{Примечания}

1. См., например: $[1 ; 2]$.

2. Подробнее см.: [3].

3. Мухаджирская комиссия (Мухаджирин комисйону) была учреждена при правительстве в январе 1860 г. в связи с массовой иммиграцией северокавказцев с целью оперативного решения вопросов их поселения $[6,114]$.

4. Гуруш (куруш) - денежная единица, сотая часть лиры. В рассматриваемый период составлял примерно $1 / 4$ французского франка.

5. Последнее утверждение может свидетельствовать о наличии у традиционной знати дополнительного мотива для стремления в Сарыкамыш в виде расчета на поселение вместе с той частью общины, которой могли быть предъявлены определенные претензии в соответствии с феодально-патриархальным правом. Судя даже по имеющимся в нашем распоряжении документам, данная группа доставила немало хлопот османским чиновникам. В архивных фондах мы не обнаружили информации о дальнейшей судьбе этих семейств. Вполне вероятно, однако, что их просьба о смене места поселения в конце концов была удовлетворена. Во всяком случае в указанный период нигде в пределах Эрзурумского вилайета, кроме карсско-сарыкамышского региона, не зафиксировано постоянных осетинских поселений, в то время как в Сарыкамыше, несмотря на нежелание властей, к середине 1860-х гг. сложился достаточно крупный осетинский анклав (см. подробнее: [2, 52-53]).

1. Тотоев М. С. К вопросу о переселении осетин в Турцию // Известия Северо-Oceтинского научно-исследовательского института. 1948. Т. XIII. Вып. 1. С. 24-46.

2. Чочиев Г. В. Осетины на Ближнем Востоке: поселение, адаптация, этносоциальная эволюция (краткий очерк) // Известия СОИГСИ. 2010. Вып. 4 (43). С. 48-66.

3. Чочиев Г.В. Роль иммиграций в истории Османской империи конца XVIII - начала XX в. // Вестник Московского университета. Серия 13: Востоковедение. 2000. № 3. С. 3-19.

4. T. C. Başbakanlık Osmanlı Arşivi (далее - BOA). A. MKT.MHM. No. 193/46.

5. BOA. A. MKT.UM. No. 425/5.

6. Saydam A. Kırım ve Kafkasya Göçleri (1856-1876). Ankara: Türk Tarih Kurumu, 1997.

7. BOA. A. MKT.MHM. No. 194/10.

8. BOA. A. MKT.UM. No. $425 / 8$.

9. BOA. A. MKT.UM. No. 484/71.

10. BOA. BEO.NGG.d. No. 758/38-1.

11. BOA. A. MKT.NZD. No. 398/7.

12. BOA. A. MKT.UM. No. 542/19.

13. BOA. İ. MVL. No. 523/23518.

14. BOA. A. MKT.MHM. No. 326/89. 